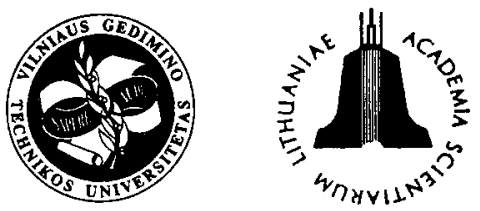

\title{
TECHNOLOGICAL AGEING INFLUENCE ON VISCOSITY OF SELECTED BITUMENS
}

\author{
Piotr Radziszewski', Robert Ziolkowski ${ }^{2}$ and Donatas Čygas ${ }^{3}$ \\ 1.2 Dept of Highway Construction, Bialystok Technical University, Wiejska str. 45E, 15-35I Bialystok, Poland \\ ${ }^{3}$ Dept of Roads, Vilnius Gediminas Technical University, Sauletekio al. 11, LT-2040 Vilnius, Lithuania \\ ${ }^{1}$ E-mail: radzisz@kmb.pb.bialystok.pl; ${ }^{2}$ E-mail: robertz@cksr.ac.bialystok.pl; ${ }^{3}$ E-mail: dcyg@ap.vtu.lt
}

Received 17 Oct 2002; accepted 15 Dec 2002

\begin{abstract}
The article presents one of the main parameters of bitumens used for asphalt concrete mixtures production viscosity. The authors analyse technological ageing process and its influence on viscosity of selected bitumens. Dependence of the viscosity of bitumens on type and amount of the additives, temperature and ageing is described through experiments. Research findings show that the employment of different types of additives increases bitumen viscosity and positively effect the bitumen ageing resistance. Practical application of presented conclusions and recommendations will enable to improve the main characteristics of asphalt concrete pavements and traffic conditions on roads.
\end{abstract}

Keywords: bitumen, viscosity, ageing resistance, additives.

\section{Introduction}

All over the world, the most widely spread road pavement is asphalt concrete pavements. They are firm, deformative, they have better cohesion with the vehicle wheels and are distinguished in other positive features [1]. Although the amount of bitumen in the asphalt concrete mixtures mostly make only $5-7 \%$ of all components, it plays an important role in assurance of firmness and durability of the pavement. Therefore, bitumen used for road construction and repairs should contain a whole set of structural and mechanical properties in the wide range of temperatures, have good cohesion and adhesion properties, be thermally stable at high temperatures, preserve its deformative and plastic properties at low environmental temperatures [2].

In accordance with the definition, viscosity is a ratio of the bitumen shearing stress that arises between two layers during the motion one over the other [3]. Viscosity exists as a result of cohesion.

Viscosity, besides the elasticity, is the main reological bitumen parameter and is highly related to the cohesion, that is the molecular force between particles within a substance that acts to unite them in the consequence of van der Waals forces [4, 5]. Cohesion and viscosity are inversely proportional to temperature; their values decrease with increasing temperature and increase when the temperature decreases. These features of bitumen are very important when applying bitumen in production and utilisation of asphalt concrete mixes.

The viscosity is the main factor in determining basing on the Bitumen Test Data Chart (BTDC) - the optimal temperature of mixing bitumen with the mineral aggregate and in specifying the lowest acceptable temperature of compaction within the technological range of temperature. Testing the viscosity in the service range of temperature enables to decide about susceptibility of road pavement to permanent deformation. The higher viscosity at $60^{\circ} \mathrm{C}$, the better deformation resistance [6].

\section{Viscosity of bitumens in technological asphalt con- crete manufacturing process}

Putting bitumen properties to analyses in the context of technological processes and conditions of work in surface of road pavement, two temperature zones can be distinguished [7]:

- service zone, that is the temperature interval in which bitumen works in pavement. It is determined by the softening point on the one hand and by the Fraass breaking point on the other (in Poland this temperature range is from about $-40^{\circ} \mathrm{C}$ to about $+70^{\circ} \mathrm{C}$ ).

- technological zone, that is the temperature interval limited by the lowest permitted temperature of compaction on the one hand, and by the highest permitted temperature of asphalt concrete mix production on the other (this temperature range is from about $90^{\circ} \mathrm{C}$ to about $240^{\circ} \mathrm{C}$ ).

Bitumen as a viscoelastic substance may exist in three different states depending on temperature:

- elastic state - when one considers bitumen at low temperatures (temperatures below the bitumen breaking point), 
- viscosity state - when bitumen is considered at high temperatures (temperatures over the bitumen softening point),

- viscoelastic state - when bitumen is situated between its breaking and softening points.

Theoretically, as long as the asphalt concrete mix temperature is higher than the bitumen softening point, the compaction process may be carried out but according to asphalt concrete mix should have a characteristic proper fluidity which is only obtained at some or above some specific temperature - the optimal temperature for the given technological process of asphalt concrete mix production [8].

According to this:

a) during the pumping process bitumen viscosity should be of $2 \mathrm{~Pa}^{*}$;

b) asphalt concrete mix production process (the process of coating grains with bitumen) should take place when the temperature is high enough and let encircle every grain with the bitumen membrane of a proper thickness. The temperature must be not too high because this could lead to flow bitumen off the grains and eventually to mix segregation. It is said that the most proper temperature is when bitumen viscosity is of $0,2 \mathrm{~Pa}^{*} \mathrm{~s}$;

c) compaction process is started right after the laying asphalt concrete mix out and is effective till the bitumen viscosity in pavement is lower than $20 \mathrm{~Pa}^{*} \mathrm{~s}$. Over that viscosity the compaction process is considered as ineffective due to a high stiffness of laid out pavement.

The hardness of bitumen within the asphalt concrete mix during compaction process is higher than the hardness of the initial bitumen which is delivered from the refinery [9]. This is due to bitumen exposition to high temperature effects during pumping and coating process. So when the temperature at which the bitumen viscosity is of $20 \mathrm{~Pa}^{*} \mathrm{~s}$ must be determined, the process of bitumen presaging ought to be also taken into consideration and the bitumen should be put to short-term ageing in TFOT test (Thin Film Oven Test).

\section{Technological ageing of bitumens}

Bitumen ageing is a physical-chemical process when its inner properties are subjected to changes during manufacturing processes (storage, transport, mixing and compaction) and eventually in road surface. So one can say, ageing is two-step process $[10,11]$ :

- technological ageing - called short-term ageing,

- service ageing - called long-term ageing.

Short-term ageing, called also technological ageing, has a disadvantageous influence on asphalt properties. Changes of bitumen properties caused by oxygen and high temperature lead to the changes of bitumen structure. They affect the hardness by reducing the penetration, increasing the softening point and viscosity. The most essential and violent ageing changes take place during mixing the aggregate with the bitumen, when every grain should be coated by a thin membrane of bitumen which thickness is 5-15 $\mu \mathrm{m}$. At this process bitumen binder is heated to a temperature of about 160$180^{\circ} \mathrm{C}$, what together with its small thickness and high temperature of aggregate creates conditions to evaporate oil components and oxidise other bitumen ingredients [12].

The thin film oven test is accepted as being a good simulation of the ageing effects occurring during manufacturing process. In this test a sample of bitumen is heated for 5 hours in a temperature of $163^{\circ} \mathrm{C}$ in special plates in a layer of $3 \mathrm{~mm}$ thickness.

Technological ageing is only one of the essential factors influencing bitumen properties. The other one that effects the viscosity is bitumen modification process. During modification the addition of different types of modifiers also influences the bitumen ageing resistance properties.

Using the Bitumen Test Data Chart and viscosity test results the optimal temperatures for technological processes were specified.

\section{Materials and experimental procedure}

In research works unmodified as well as modified bitumen were used. In modification process there were used scrap rubber of used car tires and thermoplastic elastomers (styrene-butadien-styren, SBS) of different types: kraton 1101, kraton $1184(\mathrm{PmB})$. As a result, the following bitumens were tested:

- D-50 Gd - unmodified bitumen from Gdansk Rafinery,

- D-70 Gd - unmodified bitumen from Gdansk Rafinery,

- D-50 $\mathrm{P}^{3}$ - unmodified bitumen from Plock oil Plant, D-70 $\mathrm{P}^{3}$ - unmodified bitumen from Plock oil Plant,

- D-70 Gd + 3\% kraton D 1101 (elastomeroasphalt),

- D-70 Gd + 5\% kraton D 1101 (elastomeroasphalt),

- D-70 Gd + 7\% kraton D 1101 (elastomeroasphalt),

- D-70 Gd + 3\% kraton D 1192 (elastomeroasphalt),

- D-70 Gd + 5\% kraton D 1192 (elastomeroasphalt),

- D-70 Gd + 7\% kraton D 1192 (elastomeroasphalt),

- Elastobit 80 - kraton modified bitumen

- D-70 Gd $+10 \%$ rubber (rubber-bitumen $-\mathrm{Gu} 10$ ),

D-70 Gd + 15\% rubber (rubber-bitumen - Gu 15),

D-70 Gd $+20 \%$ rubber (rubber-bitumen - Gu 20).

The viscosity test was carried out in a Brookfield Viscosymeter consisted of the computerised viscosymeter and thermostat for keeping stable temperature. The viscosity was determined at four basic temperatures: $60^{\circ} \mathrm{C}$, $90^{\circ} \mathrm{C}, 110^{\circ} \mathrm{C}$ and $135^{\circ} \mathrm{C}$ before and after short-term ageing.

\section{Analysis results}

The research results are presented on Figs 1-9 which show the viscosity dependence on the type and amount of additives (Fig 1), temperature (Figs 2-8) and increase of the viscosity as a result of ageing process (Fig 9). 


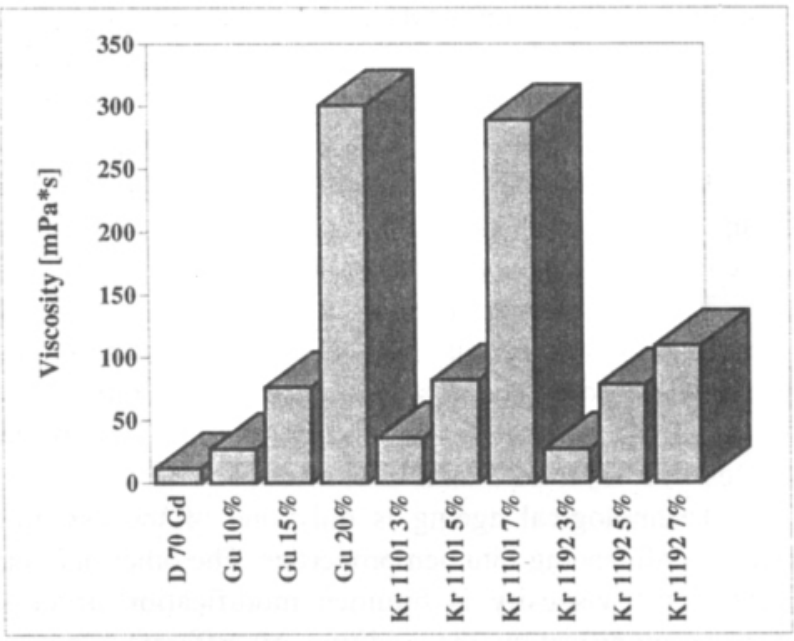

Fig 1. Influence of type and amount of additives on bitumen viscosity determined at $90{ }^{\circ} \mathrm{C}$

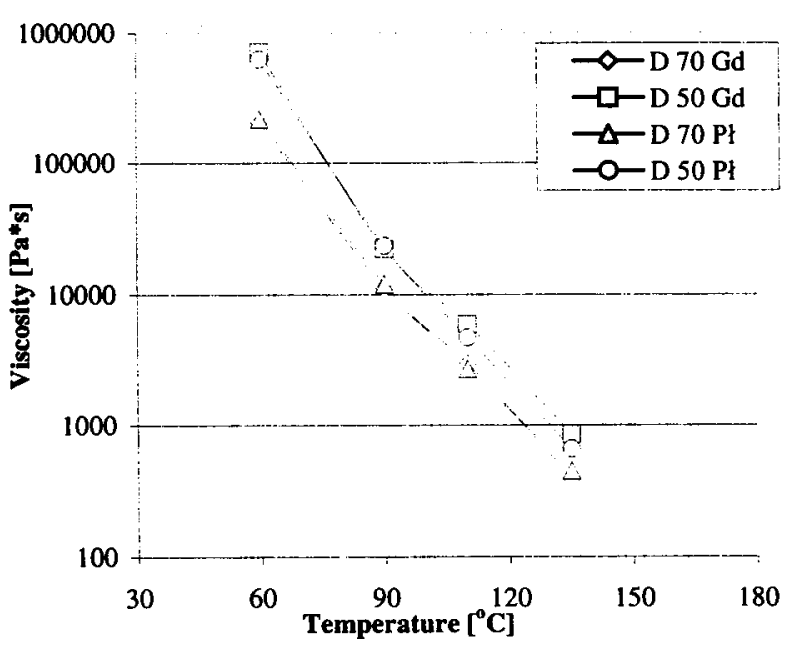

Fig 2. Influence of the temperature on standard bitumen viscosity

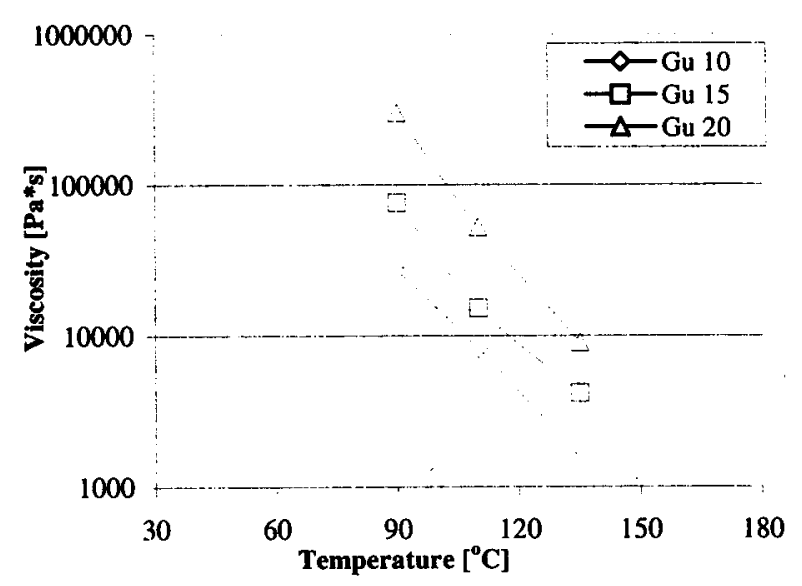

Fig 3. Influence of the temperature on the rubber-bitumen viscosity

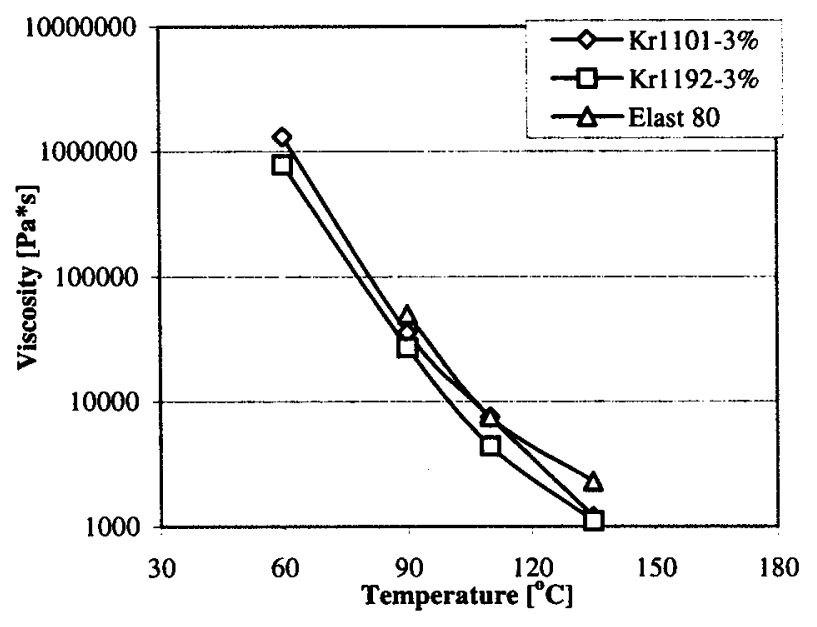

Fig 4. Influence of the temperature on PmB viscosity

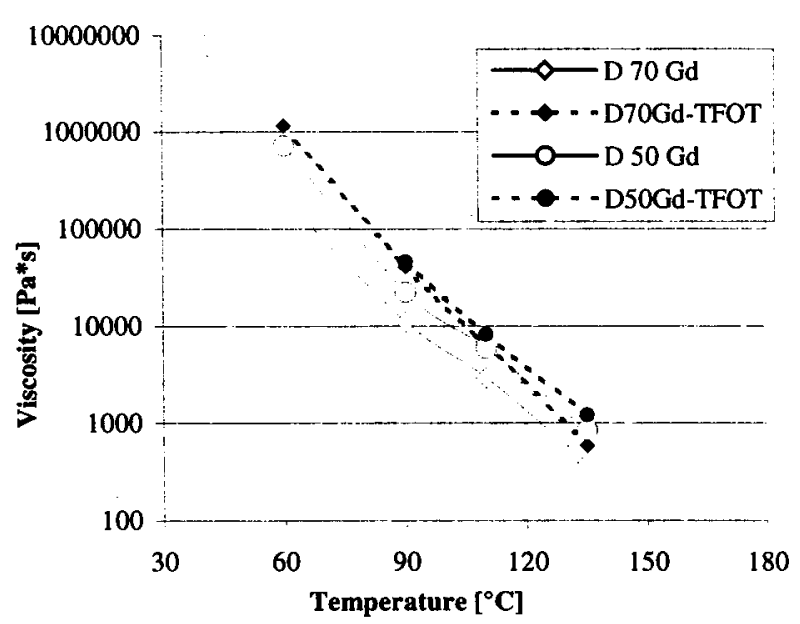

Fig 5. Ageing influence on standard viscosity of bitumen produced in Gdansk Rafinery

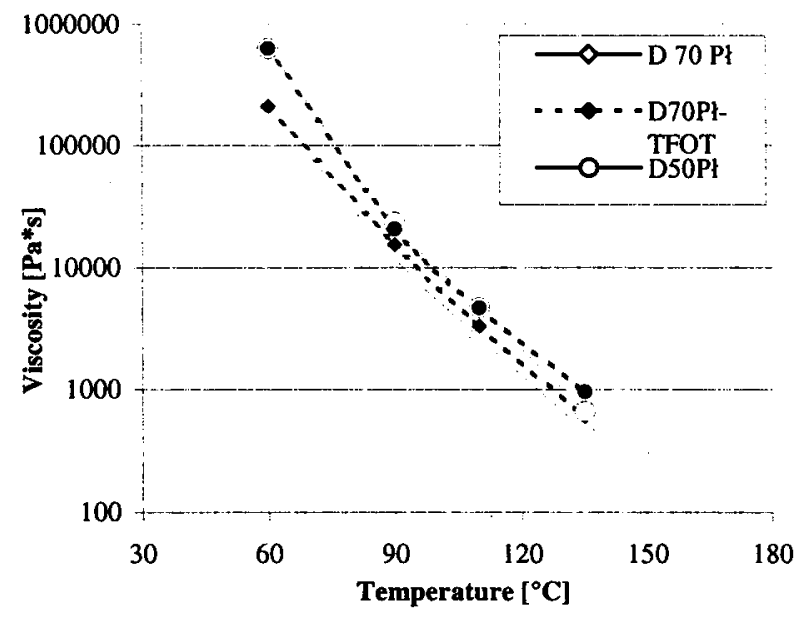

Fig 6. Ageing influence on standard viscosity of bitumen produced in Polock Oil Plant 


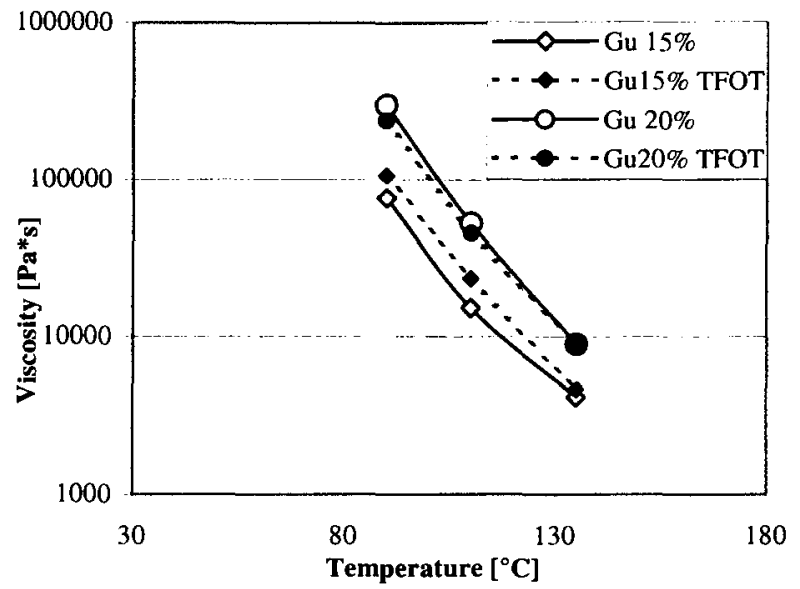

Fig 7. Ageing influence on standard rubber-bitumen viscosity

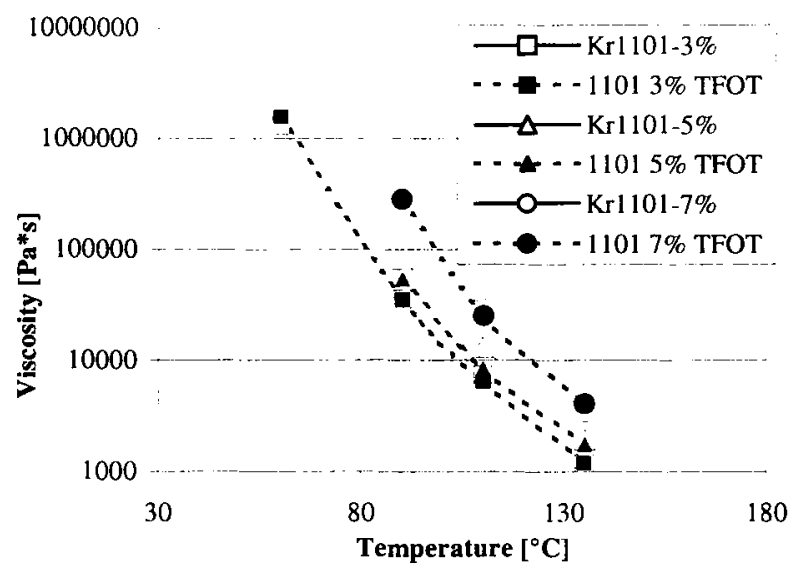

Fig 8. Ageing influence on $\mathrm{PmB}$ viscosity

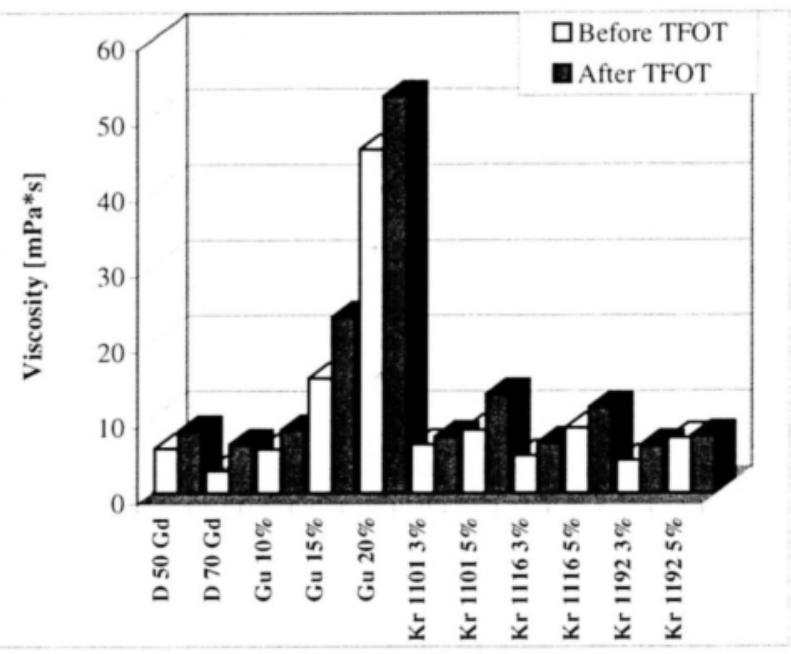

Fig 9. Changing of bitumen viscosity determined at $110^{\circ} \mathrm{C}$ as a result of TFOT ageing

Note: tests were carried out in a frame of research works founding by $\mathrm{KBN}$ including executing research project No 5 T07E02722 in 2002 and 2003

\section{Conclusions}

1. All investigated binders have hardened as a result of technological ageing process. Unmodified bitumen are more susceptible to technological ageing than the modified ones.

2. Both short-term ageing and modifiers addition contributed to asphalt viscosity increase. The increase depends on amount and type of additive - the more additives, the higher viscosity.

3. The rubber-asphalt $\mathrm{Gu} 20$ is characterised by the highest viscosity in every tested temperature comparing to elastomeroasphalt and unmodified ones (Figs $1,9)$ but, on the other hand, even at a very low modification level the SBS elastomer (3\% of kraton) brings about a huge increase of viscosity (for about $100 \%$ ) at $60{ }^{\circ} \mathrm{C}$ - the theoretically highest temperature occurring on surfaces in Polish climate.

4. Unmodified D-70 asphalt occurred to be the most susceptible with least ageing resistance (Fig 9).

5. The investigation results show the positive influence of additives on bitumen properties in the light of viscosity changes in ageing process comparing to unmodified bitumen. Lines reflecting dependence of bitumen viscosity upon the temperature before and after TFOT ageing remain almost unchanged for modified bitumen (Figs 7, 8).

6. The temperature range for compaction process - determined on the grounds of BTDC - has risen from range $103-90^{\circ} \mathrm{C}$ to range $111-98{ }^{\circ} \mathrm{C}$ for unmodified D-70 asphalt which gives almost $10 \%$ increase and actually remained unchanged for elastomeroasphalt D-70 $+7 \%$ kraton D 1192 and rubber-bitumen with $20 \%$ of rubber. Modifiers addition although in many cases increases the initial bitumen viscosity, they also very well affect bitumen ageing resistance and increases their initial resistance.

\section{References}

1. Cygas D. Main problems of manufacturing asphalt concrete mixtures in Lithuania. Civil Engineering (Statyba), Vol VI, No 1, Vilnius: Technika, 2000, p. 39-45 (in Lithuanian).

2. Cygas D., Laurinavičius A. The main problems of using asphalt concrete mixtures for pavements of automobile roads and town streets. The supplement of research journal Civil Engineering (Statyba), Vilnius: Technika, 2000, p. 20-26 (in Lithuanian).

3. Błażejowski K., Styk S. Technology of bitumen layers (Technologia warstw bitumicznych). WKŁ, Warszawa, 2000. 25 p. (in Polish).

4. Kalabińska M., Piłat J. Reology of bitumen and mineralasphalt mixes (Reologia asfaltów i mas mineralnoasfaltowych). WKL, Warszawa 1982. 41 p. (in Polish).

5. Sybilski D. Road polymer bitumen. Functional quality. Methods and criterion of evalution. Studies and materials, book 45, Road and Bridge Research Institute (Studia i 
materiały, zeszyt 45). IBDiM, Warszawa, 1996, p. 13-18 (in Polish).

6. The heavy duty surfaces. The arguments for SMA. EAPA, The Netherlands, 1998. $40 \mathrm{p}$

7. Gaweł I., Kalabińska M., Piłat J. Road bitumens (Asfalty drogowe). WKL, Warszawa, 2001. 72 p. (in Polish).

8. Croney D., Croney P. Design and performance of road pavement. NY: McGraw-Hill, 1997. 509 p.

9. Garba R., Horvli I. Prediction of rutting resistance of asphalt mixtures. Bearing capacity of roads, railways and airfields, Vol 1, Portugal, 2002, p. 839-848.
10. Amy L., Jerome F., William $O$. Rutting analysis from a different perspective. Transportation research record No 1473. Pavement Design, Management and Performance. National Academy Press, Washington, D.C., 1995, p. 9-17.

11. Mostafa A., Fonad M. Development of pavement temperature prediction model for asphalt concrete pavements. Bearing capacity of roads, railways and airfields, Vol 1, Portugal, 2002, p. 285-294.

12. Bosscher P., Hussain U., Suwitho T. Relationship between pavement temperature and weather data, Wisconsin field study to verity superpave algoritm. Transportation research record No 1609. Transportation research board, Washington D.C., 1998, p. 10-19. 